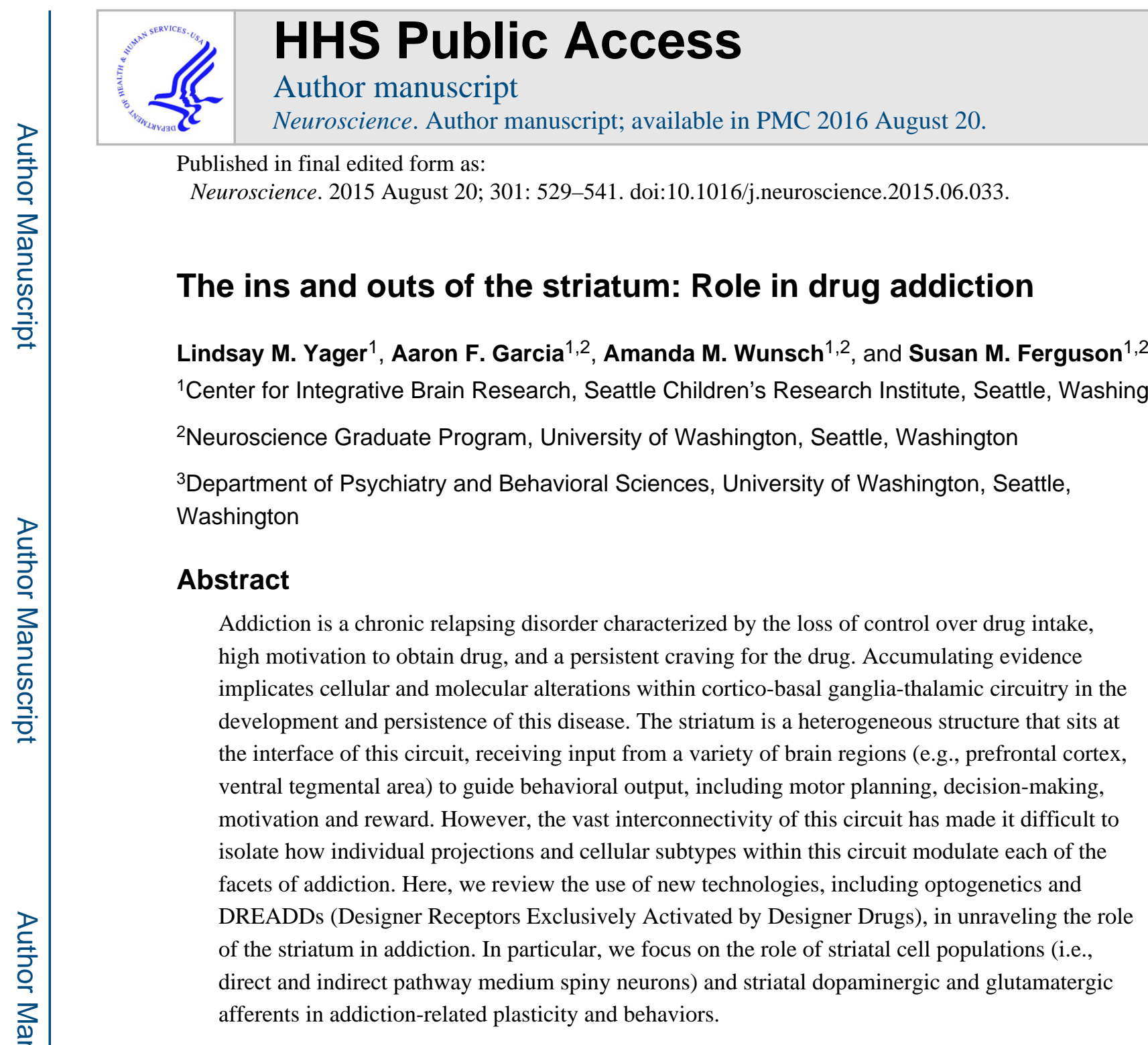

\title{
Introduction
}

Drug addiction is a costly and incapacitating disease characterized by uncontrollable drugtaking and drug-seeking, and a high likelihood for relapse, even long after the cessation of drug use. The cortico-basal ganglia-thalamic circuit (Figure 1) has long been known to regulate the development and maintenance of addictive behaviors (Lobo and Nestler, 2011, Luscher and Malenka, 2011, Nestler, 2013, van Huijstee and Mansvelder, 2014). In particular, the striatum, which serves as a central interface of the circuit, has been identified as a key site for the neuroplastic events that underlie addictive processes (Lobo and Nestler, 2011, Luscher and Malenka, 2011, Nestler, 2013, van Huijstee and Mansvelder, 2014). Nonetheless, because of the vast complexity of this circuit, our ability to gain a precise

*Corresponding author: Susan M. Ferguson, smfergus@uw.edu, Seattle Children's Research Institute, 1900 Ninth Ave., Seattle, WA 98101.

Publisher's Disclaimer: This is a PDF file of an unedited manuscript that has been accepted for publication. As a service to our customers we are providing this early version of the manuscript. The manuscript will undergo copyediting, typesetting, and review of the resulting proof before it is published in its final citable form. Please note that during the production process errors may be discovered which could affect the content, and all legal disclaimers that apply to the journal pertain. 
understanding of how the specific subcomponents and cell types within areas such as the striatum contribute to addiction has remained elusive. This review will focus on the emergence of new technologies and how they are now allowing us to advance our understanding of the role of striatal afferents and efferents in shaping this chronic, relapsing disease.

\section{Striatal circuitry}

The striatum is the major integration site of the cortico-basal ganglia-thalamic circuit, and as such receives a large variety of inputs (Figure 1). In particular, it receives cholinergic inputs from striatal interneurons and brainstem sources (e.g. laterodorsal tegmental area and the pedunculopontine nuclei) and GABAergic inputs from striatal interneurons (Kita, 1993, Dautan et al., 2014). Additionally, it receives dopaminergic inputs from the ventral tegmental area (VTA) and the substantia nigra (SNr) and glutamatergic inputs from several areas, including cortex, hippocampus, amygdala, and thalamus (Swanson, 1982, Phillipson and Griffiths, 1985, Finch, 1996, Groenewegen et al., 1999, Britt et al., 2012). These glutamatergic inputs make contact on the heads of dendritic spines of the striatal GABAergic medium spiny projection neurons (MSNs) whereas dopaminergic inputs synapse onto the spine neck, allowing for an important and complex interaction between these two inputs in modulation of MSN activity (Freund et al., 1984, Xu et al., 1989).

The striatum itself can be divided into two main regions, the dorsal striatum and the nucleus accumbens (NAc), and is comprised of multiple neuronal phenotypes including four different types of interneurons (i.e., cholinergic interneurons and GABAergic interneurons, which express either parvalbumin, calretinin, or nitric oxide synthase/neuropeptide Y/ somatostatin) (Kemp and Powell, 1971). However, the majority of striatal neurons ( 95\%) are MSNs (Kemp and Powell, 1971); these will be the focus of this review. The striatal MSNs in the dorsal striatum can be subdivided into two classes based on their projection patterns, as well as their neuropeptide and receptor expression. MSNs that send monosynaptic projections to the basal ganglia output nuclei (i.e. the $\mathrm{SNr}$ and the globus pallidus internal (GPi)) and express dopamine D1 receptors along with the neuropeptides dynorphin and substance $\mathrm{P}$, form part of the direct pathway (dMSNs). MSNs that indirectly project to basal ganglia output nuclei via the globus pallidus external (GPe) and the subthalamic nucleus (STN) and express dopamine D2 receptors and the neuropeptide enkephalin, form part of the indirect pathway (iMSNs) (Gerfen and Surmeier, 2011, Wall et al., 2013). However it should be noted that the MSN projections are not entirely segregated, as some dMSNs send axon collaterals to the GPe/ventral pallidum (VP) (Fujiyama et al., 2011).

Classically, these two striatal MSN populations are thought to have opposing effects on basal ganglia output. Activation of the dMSNs causes a net excitation of the thalamus resulting in a positive cortical feedback loop; thereby acting as a 'go' signal to initiate behavior. Activation of the iMSNs, however, causes a net inhibition of thalamic activity resulting in a negative cortical feedback loop and therefore serves as a 'brake' to inhibit behavior (Gerfen et al., 1982, Albin et al., 1989, Deniau and Chevalier, 1992, Gerfen and Surmeier, 2011, Calabresi et al., 2014). Additionally, basal ganglia output can be influenced 
via the hyperdirect pathway, which is a monosynaptic excitatory projection from the cortex to the STN that results in SNr excitation upon activation (Kita et al., 1983). Adding to the complexity of this circuit, the $\mathrm{SNr}$ itself projects back to the striatum as well as to the cortex, providing dopaminergic feedback to these structures (Gerfen et al., 1987).

Although these two striatal output pathways also exist in the NAc, the efferent targets of the MSNs are distinct from those in the dorsal striatum and the pathway segregation is much less complete. Specifically, iMSNs in the NAc (i.e., those neurons that express dopamine D2 receptors) project to the VP whereas dMSNs in the NAc (i.e., those neurons that express dopamine D1 receptors) project primarily to the VTA and $\mathrm{SNr}$ but also send axon collaterals to the VP (Chang and Kitai, 1985, Lu et al., 1998, Zhou et al., 2003, Tripathi et al., 2010, for review see Smith et al., 2013). It should also be noted that there is a small population of neurons in the NAc that coexpress both D1 and D2 receptors, though this is largely restricted to the NAc shell (Bertran-Gonzalez et al., 2008). For the purpose of providing clarity in this review, we have operationally defined dMSNs as neurons that express dopamine D1 receptors and primarily target the VTA and/or SNr whereas iMSNs are neurons that express dopamine D2 receptors and primarily target the VP or GPe. However, it is important to recognize that depending on the targeting method for a particular manipulation that was performed and the region it was performed in, the distinction between the indirect and direct striatal pathways in a given study may be less than complete.

In addition to the anatomical distinctions described above, the NAc and the dorsal striatum also differ functionally (Haber and McFarland, 1999, Berke and Hyman, 2000, Haber, 2003, Pennartz et al., 2011). Specifically, the NAc, which is typically associated with limbic areas, regulates affective components of behavior, including motivational and emotional processes (Berke and Hyman, 2000, Meredith et al., 2008, Pennartz et al., 2011). Neurons in the NAc core and NAc shell subdivisions also differ functionally. The NAc core is involved in the processing of conditioned stimuli whereas the NAc shell is more important in the processing of unconditioned stimuli; these differences are thought to be due to variations in the morphology (shell neurons are smaller and significantly less spiny) and projection patterns of these subregions (Heimer et al., 1997, Groenewegen et al., 1999, Meredith et al., 2008). In contrast, the dorsal striatum, which contains both dorsomedial and dorsolateral aspects, receives dense innervation from neocortical areas, including motor areas (Berke and Hyman, 2000). The dorsomedial striatum is important in the performance of goal-directed behaviors whereas the dorsolateral striatum regulates habitual behaviors (Everitt and Robbins, 2005, Pennartz et al., 2011). Nonetheless, the striatal sub-regions are not independent, as limbic and cortical information can be passed from the NAc shell, through the core, and to the dorsal striatum in an ascending spiral via midbrain dopamine neurons (Haber et al., 2000).

\section{Historical perspectives on how striatal circuitry regulates addiction}

Studies using classical methods (e.g., electrolytic and excitotoxic lesions, pharmacological agonists and antagonists, microdialysis) have implicated both glutamate and dopamine transmission within the striatum in the development and persistence of addiction. For example, microdialysis studies have shown increases in the concentration of these neurotransmitters within the striatum following both acute and chronic drug exposure as 
well as during relapse of drug-seeking behavior (Di Chiara and Imperato, 1988, Pierce et al., 1996, for review see Torregrossa and Kalivas, 2008). In addition, correlative studies utilizing immediate early gene expression as a marker of neuronal activation indicate the involvement of the striatum, together with its source regions of glutamate (prefrontal cortex [PFC], thalamus, amygdala and hippocampus) and dopamine (VTA and $\mathrm{SNr}$ ), in addictionrelated behaviors, including relapse and psychomotor sensitization (Table 2, Neisewander et al., 2000, Ciccocioppo et al., 2001, Ostrander et al., 2003, Kelley et al., 2005, Kufahl et al., 2009). Furthermore, lesions and pharmacological manipulations (e.g., non-selective agonists and antagonists, temporary inactivation) have confirmed a causal role for all of these regions in psychomotor sensitization and drug-taking and -seeking behaviors (Roberts and Koob, 1982, Wolf et al., 1995, Li and Wolf, 1997, Weissenborn et al., 1998, Tzschentke and Schmidt, 2000, McFarland and Kalivas, 2001, Shalev et al., 2002, Capriles et al., 2003, McFarland et al., 2003, See et al., 2007). Importantly, glutamatergic and dopaminergic projections into the striatum also appear to be critical for reinstatement of drug-seeking (Table 2) as pharmacological blockade of glutamate and dopamine receptors in the striatum prevents relapse (Park et al., 2002, Anderson et al., 2003, Bachtell et al., 2005). However, some of these studies have produced conflicting results, which is likely due to the nonspecific nature of these techniques. Furthermore, these classical methods have not allowed us to parse apart the role of specific striatal afferent and efferent projections in addictionrelated behaviors. To further complicate understanding the role of striatal circuitry in addiction, the neuronal populations within the striatum are physically intertwined, making manipulations to the distinct cell types difficult with traditional approaches and consequently limiting our knowledge of the role that each of the striatal cell populations play in the processes that govern addiction.

Thus, while lesions and pharmacological manipulations have given us insight into the broad nature of striatal circuitry regulation in addiction, these techniques lack both temporal and cellular specificity. Moreover, lesions and pharmacological manipulations cause widespread effects (e.g., effect fibers of passage), and these approaches cannot parse apart the function of specific afferent and efferent projections. Given the vast interconnectivity of this circuit, isolating the role of individual projections is critical for gaining a complete understanding of the neural mechanisms underlying addiction. Fortunately, the emergence of novel molecular and genetic technologies, such as DREADDs (Designer Receptors Exclusively Activated by Designer Drugs) and optogenetics (Table 1), has provided new methods for exploring the relationship between neural activity and addiction-related behaviors and is giving us new insight into how specific cell types and projections within the cortico-basal ganglia-thalamic circuit regulate addiction. In the following sections we will discuss recent studies that utilize these techniques to parse apart the role of striatal afferent and efferent projections in regulating addiction-like behaviors.

\section{The role of striatal direct and indirect MSNs in addiction}

As described above, the classic model of cortico-basal ganglia-thalamic circuit function proposes that the direct and indirect pathways act in an opposing, yet balanced, manner to guide a variety of behaviors, including motor- and action-planning, decision-making, and motivation. As these pathways serve to optimize behavior outcomes, it has been 
hypothesized that an imbalance between signaling in dMSNs and iMSNs may contribute to neuropsychiatric diseases, such as addiction (Lobo and Nestler, 2011, Smith et al., 2013, Volkow et al., 2013). However, until recently, it has been difficult to systematically study the contributions of these two striatal pathways to both normal and pathological behaviors. The advancement of molecular and genetic tools, including cell-specific viral-mediated gene transfer, expression of targeted toxins, fluorescent reporter mice, transgenic mice, and the development of novel classes of receptors, channels and calcium indicators are providing us with a means for visualizing and transiently altering neuronal activity in a highly selective manner. Thus, advancements in technology are now allowing us to begin to untangle the role of these striatal output pathways in behavior. For example, selective activation of dorsal striatal dMSNs, via light activation of channelrhodopsin 2 (ChR2, Table 1), initiates movement and reduces freezing in an open field while selective activation of dorsal striatal iMSNs decreases movement and increases freezing behavior (Kravitz et al., 2010). These data suggest that these two pathways do indeed work in opposition to promote normal behavior, as has previously been hypothesized. Next we will discuss the role of dMSNs and iMSNs in regulating addiction-related behaviors.

\section{Effects of cocaine on neuronal signaling in direct and indirect striatal neurons}

There is abundant evidence that psychostimulants such as cocaine induce different cellular and molecular adaptations in dMSNs and iMSNs (for review see Lobo and Nestler, 2011). It has remained unclear, however, what effect these drugs have on the temporal dynamics of neuronal signaling in vivo in these different neuronal populations. This issue was recently addressed with in vivo optical imaging studies (Table 1) using a fluorescent calcium indicator in reporter mice that expressed green fluorescent protein (GFP) in either dMSNs or iMSNs to measure cocaine-induced changes in intracellular calcium responses (a measure of neuronal activation) of dorsal striatal MSNs in naïve and chronically cocaine-treated mice (Luo et al., 2011, Park et al., 2013). An injection of cocaine in naïve mice increased the concentration of calcium in dMSNs while simultaneously decreasing the concentration of calcium in iMSNs; thus, shifting the balance of signaling to dMSNs (Luo et al., 2011). Although an injection of cocaine in mice chronically treated with cocaine resulted in blunted calcium responses in both dMSNs and iMSNs, this blunted effect was longer lasting in iMSNs, resulting in a net shift in the predominance of signaling to dMSNs (Park et al., 2013). Interestingly, chronically treated mice also displayed a decrease in baseline calcium events in iMSN (but not dMSNs), suggesting repeated cocaine exposure produces a generalized chronic shift in signaling to dMSNs. Together these data indicate that both acute and repeated cocaine exposure shifts the predominance of neuronal signaling to the direct pathway, and this altered balance in striatal pathway activity may facilitate continued drug use in addicts.

\section{Role of direct pathway MSNs in addiction-related behaviors}

There is considerable evidence implicating a role for dMSNs in drug reward. For example, antagonism of dopamine D1 receptors, which are predominately expressed in dMSNs, blocks expression of a cocaine conditioned place preference (CPP, Table 2) (Hiroi and White, 1991, Baker et al., 1998). However, it was not until recently that cell-specific 
technologies have allowed us to expanded upon these findings to understand the functional role of dMSNs in reward and motivation.

In particular, it was found that pairing optogenetic activation (via ChR2) of NAc core and shell dMSNs with a subthreshold dose of cocaine during conditioning produced a place preference for the cocaine-paired compartment (Lobo et al., 2010). Importantly, stimulating NAc core and shell dMSNs in the absence of cocaine did not result in a preference for the laser-paired chamber suggesting that the preference for the cocaine-paired chamber was not simply driven by a preference for laser stimulation. Nonetheless, it has been shown that optogenetic activation of dorsal striatum dMSNs is inherently reinforcing, because mice will work to receive stimulation of dMSNs in this area and laser stimulation of these neurons in a CPP paradigm is sufficient to induce a preference for the laser-paired chamber (Kravitz et al., 2012). Although these differences in behavior could be due to variation in stimulation parameters, they may also reflect a differential role in reward processing played by each striatal subregion. Consistent with the Lobo et al. (2010) findings, transient inhibition of synaptic transmission in NAc core and shell dMSNs during cocaine conditioning, via doxycycline-dependent expression of tetanus toxin, attenuated the development of a cocaine-induced place preference (Hikida et al., 2010). Together these data suggest that dMSN activity regulates the rewarding effects of cocaine.

In order to assess the role of dMSNs in drug-induced psychomotor sensitization, another paradigm commonly used to study the mechanisms underlying addiction, we used a celltype specific chemogenetic DREADD receptor approach to ask whether decreasing neuronal excitability of dorsal striatal dMSNs would inhibit this behavior. We found that decreasing activity of dMSNs by activation of $\mathrm{G}_{\mathrm{i} / \mathrm{o}}$-coupled DREADDs during repeated amphetamine treatment blocked the persistence of locomotor sensitization (Ferguson et al., 2011). In line with these results, both optogenetic inhibition of NAc core and shell dMSNs and reversible blockade of neurotransmission in NAc core and shell dMSNs attenuated the development of cocaine-induced locomotor sensitization (Hikida et al., 2010, Chandra et al., 2013). Interestingly, although optogenetic stimulation of NAc core and shell dMSNs had no effect on baseline locomotor activity in drug-naïve mice, optogenetic stimulation was sufficient to produce a locomotor response in mice that had received repeated cocaine treatment, suggesting an increase in the reactivity of dMSNs to stimulation following cocaine exposure (Lobo et al., 2010).

While these studies have led to a better understanding of the role of dMSNs in the rewarding and psychomotor sensitizing effects of drugs, there has only been one study to date that directly assessed the role of dMSNs in an animal model of relapse. It was found that optical inhibition of NAc core projections to the $\mathrm{SNr}$ (i.e., those from dMSNs) failed to alter cocaine-plus-cue-induced reinstatement behavior (Stefanik et al., 2013). Nonetheless, it is possible that dMSNs may play an important role in different triggers of relapse, such as stress- or context-induced reinstatement, as these different types of relapse are thought to rely on dissociable, though overlapping, neural circuitry (Cardinal et al., 2002, Bossert et al., 2013). It will be important in future studies to parse out the role of dMSNs in other instigators of drug relapse (Table 2). 


\section{Role of indirect pathway MSNs in addiction-related behaviors}

In opposition to the direct pathway, which acts as a 'go' signal to promote behavior, it is thought that the indirect pathway acts as a 'brake' to stop or inhibit behavior (Albin et al., 1989, Gerfen and Surmeier, 2011). While the focus of much work has been on the role of dMSNs in modulating addictive behavior, there is also mounting evidence that iMSNs play a role in motivation and addiction (Lobo and Nestler, 2011, Grueter et al., 2013). For example, optogenetic activation of NAc core and shell iMSNs suppressed the development of a cocaine CPP whereas selective ablation of NAc core and shell iMSNs via Cre recombinase-mediated expression of diphtheria toxin (Table 1) enhanced the development and the persistence of an amphetamine CPP (Durieux et al., 2009, Lobo et al., 2010). These findings suggest that iMSNs can bidirectionally modulate drug reward.

To assess the role of iMSNs in amphetamine-induced psychomotor sensitization, we used activation of $\mathrm{G}_{\mathrm{i} / \mathrm{o}}$-coupled DREADDs to transiently reduce activity of dorsal striatum iMSNs during an amphetamine sensitization protocol that normally produces threshold levels of sensitization (Ferguson et al., 2011). We found that decreasing activity of iMSNs during repeated amphetamine exposure enhanced the development and persistence of sensitization. Consistent with these results, both optogenetic and chemogenetic activation of NAc core and shell iMSNs, by ChR2 and $\mathrm{G}_{\mathrm{s}}$-coupled DREADDs respectively, during amphetamine treatment prevented the development and persistence of locomotor sensitization (Chandra et al., 2013, Farrell et al., 2013). In addition, optogenetic activation of NAc core and shell iMSNs during drug withdrawal subsequently attenuated the expression of sensitization to cocaine, suggesting that neuroplastic changes, such as changes in gene expression and synaptic remodeling, in iMSNs during drug withdrawal are critical for the persistence of this addiction-related behavior (Song et al., 2014).

Recently, the role of iMSNs in the motivation to self-administer cocaine (Table 2) has been explored, and it was found that optogenetic activation of iMSNs in the NAc core suppressed cocaine self-administration while inhibition of NAc core (but not dorsal striatum) iMSNs via

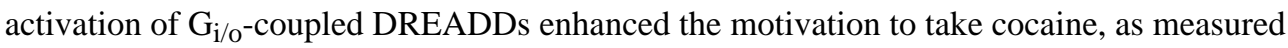
by a progressive ratio test (Table 2, Bock et al., 2013). Importantly, these results were not driven by a general increase in motivation because inhibition of iMSNs had no effect on responding for a food reward. Interestingly, these researchers also examined changes in synaptic plasticity in MSNs following cocaine self-administration and found that all mice exhibited synaptic potentiation of glutamatergic inputs onto dMSNs, but this potentiation was only seen in iMSNs in mice that did not show compulsive behaviors (defined in Table 2) following drug use (Bock et al., 2013). Together these data suggest that iMSNs normally act to restrain drug-taking behavior and recruitment of these neurons may in fact be protective against the development of compulsive drug use.

The role of iMSNs has also been examined in relapse of drug-seeking behavior and it was found that optical inhibition of NAc core projections to VP (i.e., those from iMSNs) attenuated cocaine-plus-cue-induced reinstatement (Stefanik et al., 2013). Although this finding is in contrast to the series of studies discussed above showing that iMSNs normally act to inhibit cocaine reward and behavioral sensitization, it suggests that the indirect pathway regulates addiction-related behaviors in a more complex manner than the traditional 
"go-brake" model would predict. Nonetheless, as described earlier, there is considerable evidence that projections through the NAc core indirect striatal pathway arise from both dopamine D1- and D2-expressing neurons (for review see Smith et al., 2013). It may be that D1- and D2-expressing NAc core MSNs that project to the VP differentially regulate reinstatement of drug-seeking, but additional studies would be needed to parse this out, as it cannot be determined from the optogenetic approach utilized by Stefanik et al. (2013).

\section{The role of striatal dopamine inputs in addiction}

Both the NAc and the dorsal striatum receive dense innervation from midbrain dopamine neurons, and these inputs have long been implicated in addictive behaviors (Swanson, 1982, Robinson and Berridge, 1993, Berke and Hyman, 2000, Everitt and Robbins, 2005, Gerfen and Surmeier, 2011). In particular, the primary pharmacological effects of psychostimulants are on dopamine release and reuptake mechanisms and while not their primary site of action, all other classes of abused drugs also increase striatal dopamine levels (Di Chiara and Imperato, 1988, White and Kalivas, 1998, Willuhn et al., 2010, Vander Weele et al., 2014). Since dMSNs express excitatory, $\mathrm{G}_{\mathrm{s} / \mathrm{olf}}$-coupled dopamine D1 receptors and iMSNs express higher affinity, inhibitory $\mathrm{G}_{\mathrm{i} / \mathrm{o}}$-coupled dopamine $\mathrm{D} 2$ receptors, drug-induced dopamine release has opposite effects on these two classes of MSNs. In addition, dopamine can have profoundly different effects on the plasticity of cortical inputs to these two striatal cell populations (Gerfen and Surmeier, 2011, Baik, 2013). For example, rewarding events (e.g. drug-taking) lead to dopamine release in the striatum, which promotes long-term potentiation (LTP) in cortical synapses onto dMSNs while simultaneously producing longterm depression (LTD) in iMSNs. Conversely, during non-rewarding events, dopamine neurons pause, resulting in decreased dopamine release in the striatum, which increases the strength of cortical synapses onto iMSNs and reduces the strength of cortical synapses onto dMSNs (Reynolds et al., 2001, Tang et al., 2001, Calabresi et al., 2007, Kreitzer and Malenka, 2007, Cohen and Frank, 2009, Gerfen and Surmeier, 2011, Hong and Hikosaka, 2011).

Recent advances in neurotransmitter detection, such as fast scan cyclic voltammetry (FSCV, Table 1), are now allowing us to detect in vivo dopamine release in the striatum on a subsecond scale time resolution thereby providing a means for studying the temporal dynamics of phasic dopamine signaling. This method has highlighted that contingent versus noncontingent drug administration results in different patterns of dopamine signaling in the NAc core (Stuber et al., 2005). In addition, it has been found that phasic signaling events occur to both cues and drugs during drug-seeking and drug-taking behaviors, and surprisingly these events are actually larger for the drug-associated cues (Phillips et al., 2003, Stuber et al., 2005). More recently, FSCV has been used to track phasic dopamine signals to drugassociated cues over time, and it was shown that phasic dopamine signaling patterns in the striatum vary across subregion (i.e., ventromedial and dorsolateral striatum) and by stage of drug-taking (i.e., early vs. late), but decline in response to escalating cocaine administration (Willuhn et al., 2012, Willuhn et al., 2014). FSCV, therefore, has proven important for disentangling the role of phasic dopamine signaling in the striatum in motivated behaviors and learned associations during addiction-related behaviors. 
Although novel technologies are now allowing us to demonstrate the importance of midbrain dopamine in reward behaviors (see Lenz and Lobo, 2013 for review), surprising little has been done to investigate the role of dopaminergic projections to the striatum in addictive behaviors. In one study, combining optogenetic stimulation of VTA terminals in the NAc with a subthreshold dose of morphine during conditioning produced a CPP for the morphine-paired compartment (Koo et al., 2012). In addition, optical inhibition of VTA projections to the NAc core significantly reduced cocaine-plus-cue induced reinstatement (Table 2, Stefanik et al., 2013). These findings fit with dopamine's purported role in motivation and reward and emphasize the necessity for future investigations into the role of specific dopaminergic projections in reward and addiction.

\section{Role of striatal glutamatergic afferents in addiction}

The striatum not only receives dense dopamine projections from the VTA and SNr, but it also receives innervation from glutamatergic projection neurons originating in multiple brain regions. Each of these glutamatergic inputs is thought to regulate distinct aspects of the behaviors associated with addiction (Sesack and Grace, 2010). The cortex is the predominant source of striatal glutamate and corticostriatal projections display topographic specificity, such that more dorsolateral regions of the striatum receive projections from sensorimotor cortex and more ventromedial portions of the striatum receive projections from associative cortex, including PFC (McGeorge and Faull, 1989, Groenewegen et al., 1990, Koob and Volkow, 2010, Sesack and Grace, 2010, Wall et al., 2013). Within the NAc, the PFC projections can be further subdivided with the infralimbic region projecting primarily to the NAc shell and the prelimbic region projecting primarily to the NAc core (Sesack et al., 1989, Brog et al., 1993). In addition, cortical neurons can be split into two subtypes based on their projection targets. Intratelencephalic (IT-type) neurons project both ipsilaterally and bilaterally within the telencephalon whereas pyramidal tract (PT-type) neurons project to the brainstem and send collaterals throughout the brain, including to the striatum. IT-type neurons are thought to synapse primarily on dMSNs whereas PT-type neurons are thought to project primarily to iMSNs (Reiner et al., 2010, Shepherd, 2013, but see Kress et al., 2013).

The second largest source of striatal glutamate originates in the thalamus (Lei et al., 2013, Wall et al., 2013). Midline and intralaminar thalamic structures, including the paraventricular nucleus, mediodorsal, central median, and parafasicular nuclei, send dense glutamatergic projections to the striatum and synapse directly onto both dMSNs and iMSNs (Berendse and Groenewegen, 1990, Li and Kirouac, 2008, Haber and Calzavara, 2009, Lei et al., 2013, Wall et al., 2013). Finally, the amygdala and hippocampus provide glutamatergic inputs mostly to ventral striatum and both of these projections appear to synapse primarily on dMSNs (Groenewegen and Trimble, 2007, Britt et al., 2012, MacAskill et al., 2012, Pascoli et al., 2012, Wall et al., 2013, MacAskill et al., 2014). Although new technologies are being used to refine the role of each of these sources of striatal glutamate in addiction-related behaviors, in this section we will focus on the studies that specifically probed the role of the glutamatergic afferents into the striatum. 


\section{Prefrontal Cortex}

Dysregulation of the PFC following drug use is widely believed to underlie the loss of inhibitory control seen in drug addicts and is a primary contributing factor in relapse (Kalivas, 2009, Goldstein and Volkow, 2011). Work in rodent models has found that the prelimbic and infralimbic areas of the PFC are particularly important for regulating drugseeking and the expression of addiction-related behaviors such as psychomotor sensitization and discrimination between levers during self-administration paradigms (Seamans et al., 2008, Francis et al., 2014, Moorman et al., 2014, Pascoli et al., 2014).

Although the PFC has widespread and reciprocal projections within the cortico-basal ganglia-thalamic circuit, recent studies support the idea that both drug-induced neuroplasticity in MSNs and drug-induced behaviors are modulated specifically by PFC afferents to the NAc shell. For example, infralimbic inputs to the NAc shell were found to undergo silent synapse based remodeling following withdrawal from cocaine selfadministration that was dependent on the insertion of calcium-permeable AMPA receptors, and reversal of this silent-synapse based remodeling via optical stimulation enhanced cueinduced cocaine seeking (i.e., incubation of craving, Table 2) (Ma et al., 2014). Similarly, using optical stimulation of infralimbic terminals within the NAc shell of fluorescentlylabeled dopamine D1 or dopamine D2 BAC transgenic mice, it was found that withdrawal from cocaine self-administration resulted in enhanced glutamatergic signaling in D2 MSNs (dMSNs) but not D1 MSNs (iMSNs) that was also due to insertion of calcium-permeable AMPA receptors (Pascoli et al., 2014). Although using an optical stimulation LTD protocol to restore normal transmission selectively in these inputs prior to cue-induced reinstatement also increased lever responding, it did so non-discriminatively (Pascoli et al., 2014). Nonetheless, using this method to normalize transmission prior to a cocaine challenge was sufficient to block the expression and persistence of cocaine-induced locomotor sensitization (Pascoli et al., 2012).

Studies have also begun to explore the role of PFC inputs into the NAc core in addictionrelated plasticity and behavior. Similar to the NAc shell, withdrawal from cocaine selfadministration also produced silent synapse remodeling in prelimbic inputs to NAc core MSNs, but this occurred via a mechanism that was dependent on non-calcium permeable AMPA receptor insertion (Ma et al., 2014). Furthermore, reversal of this silent-synapse based remodeling via optical stimulation inhibited cue-induced cocaine seeking (Ma et al., 2014). Likewise, optical inhibition of prelimbic afferents to the NAc core during reinstatement reduced cocaine seeking during both cocaine-primed reinstatement and cocaine-plus-cue-induced reinstatement (Stefanik et al., 2013, Stefanik et al., 2015).

It is likely that these post-synaptic neuroadaptations at corticostriatal synapses are at least partly due to drug-induced presynaptic alterations in neurotransmitter release. In support of this, optogenetic stimulation of PFC inputs to the NAc shell following either contingent or non-contingent cocaine administration revealed an increase in release probability at both short and long withdrawal periods, although the probability of neurotransmitter release was higher in mice that had self-administered cocaine compared to those that had received experimenter-administered drug (Suska et al., 2013). 
Together, these studies support the idea of dissociable roles of PFC projections to the NAc core and shell in regulating addiction behavior and associated plasticity, although it is clear that the manner in which they do so is complex. In addition, it should be noted that changes in plasticity at corticostriatal synapses within the NAc are not always observed following repeated drug treatment (Britt et al., 2012). Multiple factors, including amount of drug intake, contingency of drug administration and withdrawal time influence the neurobiological changes that occur following drug use. Likewise, experimental variables such as optical stimulation parameters and the subset of cells that are targeted within a striatal or cortical region can also have a big impact on experimental outcomes. Thus, additional work to normalize such variables will be required to gain a full understanding of the role cortical inputs into striatum play in addiction processes.

\section{Amygdala}

The amygdala is thought to regulate conditioned responses to cues associated with drugtaking (Goldstein and Volkow, 2002, Kalivas and Volkow, 2005, Bossert et al., 2013). However, relatively few studies have directly assessed neurobiological changes in amygdala projections to striatum and their contribution to addiction-related behavior. Following a cocaine sensitization protocol, it was found that optogenetic stimulation of basolateral amygdala (BLA) inputs to the NAc shell selectively enhanced excitatory post-synaptic currents and increased spine density in dMSNs, suggesting that cocaine-induced alterations in dMSN function and structure are due to an increase in the strength of BLA inputs to these neurons (MacAskill et al., 2014). However, other studies using optical stimulation of BLA inputs to the NAc shell following either cocaine self-administration or behavioral sensitization did not observe alterations in plasticity of striatal neurons (Suska et al., 2013, Pascoli et al., 2014). Nonetheless, these striatal glutamatergic afferents from the BLA appear to regulate incubation of craving and drug-seeking. For example, following cocaine selfadministration and extinction, optical inhibition of BLA inputs to the NAc core during cueinduced reinstatement decreased cocaine-seeking (Stefanik and Kalivas, 2013). In addition, it was found that the incubation of cue-induced cocaine seeking normally seen following prolonged withdrawal could be blocked by an optical stimulation LTD protocol that reversed the maturation of silent synapses in BLA inputs to the NAc shell (Lee et al., 2013). Thus, while the extent to which BLA projections to the striatum contribute to changes in MSN plasticity is unclear, there is ample evidence to support the role of these projections in regulation of the development of conditioned responses to cues associated with drug-taking as well as drug-craving. Therefore, these projections are a strong candidate for therapeutic interventions that could mitigate relapse.

\section{Hippocampus}

The hippocampus is thought to be involved in the formation of associations related to the context associated with drug-taking and may regulate the strength of responding during reinstatement (Koob and Volkow, 2010, Francis et al., 2014, Pascoli et al., 2014). Optical stimulation of ventral hippocampus afferents to the NAc shell paired with electrophysiology recordings from fluorescently-labeled dopamine D1 receptor or dopamine D2 receptor BAC transgenic mice demonstrated that cocaine self-administration increased synaptic plasticity of these inputs onto dMSNs but not iMSNs (Pascoli et al., 2014). Alterations in synaptic 
plasticity within the NAc shell MSNs at ventral hippocampus synapses have also been observed following behavioral sensitization to cocaine (Britt et al., 2012). In addition, optical inhibition of ventral hippocampus terminals in the NAc shell blocked cocaine sensitization whereas optical stimulation enhanced this behavior (Britt et al., 2012). Furthermore, optical stimulation of these projections is rewarding in and of itself, as evidenced by the development of a CPP for a chamber paired with light stimulation (Britt et al., 2012). Finally, using an optical stimulation LTD protocol to restore normal transmission selectively in hippocampal inputs to the NAc shell prior to cue-induced reinstatement resulted in decreased cocaine-seeking (Pascoli et al., 2014). Additionally, cocaine-seeking was completely abolished when normal transmission was restored to both PFC and hippocampal inputs (Pascoli et al., 2014). Together, these studies provided evidence that drug exposure increases synaptic plasticity in ventral hippocampus projections to dMSNs, which leads to an enhancement in contextual-mediated associations within the drug-taking environment. However, in contrast to these findings, ventral hippocampal inputs to the NAc shell were actually dampened in dMSNs three days after a sensitizing regimen of cocaine (MacAskill et al., 2014). These discrepant findings may reflect a differential involvement of ventral hippocampus in early versus late withdrawal, as well as differences in experimental parameters.

\section{Thalamus}

Although the thalamus densely innervates the striatum, it has largely been overlooked when studying the circuitry underlying addiction. Nonetheless, mounting evidence suggests that thalamic impairments contribute to the sensory processing and attentional deficits seen in addicts, and may also modulate drug-craving and other addiction-related behaviors (Koob and Volkow, 2010, Martin-Fardon and Boutrel, 2012, James and Dayas, 2013). For example, cFos is upregulated in the paraventricular nucleus of the thalamus (PVT) following an acute injection of either cocaine or amphetamine as well as after exposure to drugassociated cues or contexts (Deutch et al., 1998, Hamlin et al., 2009, Rotllant et al., 2010, James et al., 2011). Furthermore, lesions of the PVT enhance the acute locomotor response to an injection of cocaine, but block psychomotor sensitization and prevent context-induced reinstatement (Young and Deutch, 1998, Hamlin et al., 2009). The mediodorsal nucleus of the thalamus (MD) has also been implicated in regulating responses to psychostimulants, as lesions of the MD attenuate cocaine intake during self-administration (Weissenborn et al., 1998). However, despite evidence indicating that mediodorsal thalamus (MD) neurons are active during cue-induced reinstatement, inactivation of MD did not alter cocaine-primed or stress-induced reinstatement (McFarland and Kalivas, 2001, McFarland et al., 2004, James et al., 2011). These data suggest that the various midline thalamic nuclei may differentially regulate aspects of addiction-related behavior. However, even though the thalamus sends a strong glutamatergic projection to the striatum, there have been no studies to date utilizing more recent technology that allow for precise temporal and spatial control to define the specific role of these thalamic projections in addiction. 


\section{Concluding Remarks}

This review has focused on how the emergence of new technologies is refining our understanding of the ways in which striatal cell populations are engaged by drugs and associated stimuli, and how striatal afferents and efferents regulate the development of behaviors related to addiction. In particular, we have explored how targeted approaches are now allowing us to visualize (e.g., FCSV, calcium imaging) and manipulate with high spatial and temporal resolution (e.g., DREADDs, optogenetics) processes that are occurring at the cell-specific and/or synapse-specific level in order to map the connections that govern addiction. Although this work is just beginning, it is evident that the circuit is more complex and dynamic than has been revealed previously. In addition, it is now clear that the pattern and source of dopamine and glutamate neurotransmission is as critical, if not more so, than the absolute level for shaping drug-induced neuroplastic events and related behaviors. Nonetheless, we know that variations in behavioral paradigms and technique parameters can have a huge impact on experimental outcomes, therefore, systematic studies that carefully control for these variables must be conducted before definitive conclusions can be drawn.

An imbalance between direct and indirect striatal pathway activity has been hypothesized to mediate a transition to addiction, and current work utilizing cell-specific approaches supports this idea. However, given that dMSNs send axon collaterals to outputs of the indirect pathway and many of the studies described in this review utilized techniques that manipulated dMSNs at the level of the striatum, it will be necessary to perform experiments in the target regions of dMSNs and iMSNs to fully resolve the contributions of these two pathways in addiction behaviors. Recent anatomical studies have revealed that glutamatergic projections, both within and across structures, display differential selectivity for dMSNs and iMSNs and raise the intriguing possibility that the direct and indirect pathways should be extended to include these afferent inputs. Future studies will be necessary to determine whether other striatal afferents share this preferential innervation of a particular striatal cell type, as well as what the functional implications of extending these pathways are to addiction.

\section{Acknowledgments}

This work was supported by grants from the National Institute on Drug Abuse (T32DA007278 to AG and R01DA036582 to SMF).

\section{References}

Albin RL, Young AB, Penney JB. The functional anatomy of basal ganglia disorders. Trends Neurosci. 1989; 12:366-375. [PubMed: 2479133]

Allen BD, Singer AC, Boyden ES. Principles of designing interpretable optogenetic behavior experiments. Learn Mem. 2015; 22:232-238. [PubMed: 25787711]

Anderson SM, Bari AA, Pierce RC. Administration of the D1-like dopamine receptor antagonist SCH-23390 into the medial nucleus accumbens shell attenuates cocaine priming-induced reinstatement of drug-seeking behavior in rats. Psychopharmacology. 2003; 168:132-138. [PubMed: 12491029]

Bachtell RK, Whisler K, Karanian D, Self DW. Effects of intra-nucleus accumbens shell administration of dopamine agonists and antagonists on cocaine-taking and cocaine-seeking behaviors in the rat. Psychopharmacology. 2005; 183:41-53. [PubMed: 16163523] 
Baik JH. Dopamine signaling in reward-related behaviors. Front Neural Circuits. 2013; 7:152. [PubMed: 24130517]

Baker DA, Fuchs RA, Specio SE, Khroyan TV, Neisewander JL. Effects of intraaccumbens administration of SCH-23390 on cocaine-induced locomotion and conditioned place preference. Synapse. 1998; 30:181-193. [PubMed: 9723788]

Bardo MT, Bevins RA. Conditioned place preference: what does it add to our preclinical understanding of drug reward? Psychopharmacology. 2000; 153:31-43. [PubMed: 11255927]

Belin-Rauscent A, Fouyssac M, Bonci A, Belin D. How Preclinical Models Evolved to Resemble the Diagnostic Criteria of Drug Addiction. Biol Psychiatry. 2015

Berendse HW, Groenewegen HJ. Organization of the thalamostriatal projections in the rat, with special emphasis on the ventral striatum. J Comp Neurol. 1990; 299:187-228. [PubMed: 2172326]

Berke JD, Hyman SE. Addiction, dopamine, and the molecular mechanisms of memory. Neuron. 2000; 25:515-532. [PubMed: 10774721]

Bertran-Gonzalez J, Bosch C, Maroteaux M, Matamales M, Herve D, Valjent E, Girault JA. Opposing patterns of signaling activation in dopamine D1 and D2 receptor-expressing striatal neurons in response to cocaine and haloperidol. J Neurosci. 2008; 28:5671-5685. [PubMed: 18509028]

Bock R, Shin JH, Kaplan AR, Dobi A, Markey E, Kramer PF, Gremel CM, Christensen CH, Adrover MF, Alvarez VA. Strengthening the accumbal indirect pathway promotes resilience to compulsive cocaine use. Nat Neurosci. 2013; 16:632-638. [PubMed: 23542690]

Bossert JM, Marchant NJ, Calu DJ, Shaham Y. The reinstatement model of drug relapse: recent neurobiological findings, emerging research topics, and translational research. Psychopharmacology. 2013; 229:453-476. [PubMed: 23685858]

Britt JP, Benaliouad F, McDevitt RA, Stuber GD, Wise RA, Bonci A. Synaptic and behavioral profile of multiple glutamatergic inputs to the nucleus accumbens. Neuron. 2012; 76:790-803. [PubMed: 23177963]

Brog JS, Salyapongse A, Deutch AY, Zahm DS. The patterns of afferent innervation of the core and shell in the "accumbens" part of the rat ventral striatum: immunohistochemical detection of retrogradely transported fluoro-gold. J Comp Neurol. 1993; 338:255-278. [PubMed: 8308171]

Buch T, Heppner FL, Tertilt C, Heinen TJ, Kremer M, Wunderlich FT, Jung S, Waisman A. A Creinducible diphtheria toxin receptor mediates cell lineage ablation after toxin administration. Nat Methods. 2005; 2:419-426. [PubMed: 15908920]

Calabresi P, Picconi B, Tozzi A, Di Filippo M. Dopamine-mediated regulation of corticostriatal synaptic plasticity. Trends Neurosci. 2007; 30:211-219. [PubMed: 17367873]

Calabresi P, Picconi B, Tozzi A, Ghiglieri V, Di Filippo M. Direct and indirect pathways of basal ganglia: a critical reappraisal. Nat Neurosci. 2014; 17:1022-1030. [PubMed: 25065439]

Capriles N, Rodaros D, Sorge RE, Stewart J. A role for the prefrontal cortex in stress- and cocaineinduced reinstatement of cocaine seeking in rats. Psychopharmacology. 2003; 168:66-74. [PubMed: 12442201]

Cardinal RN, Parkinson JA, Hall J, Everitt BJ. Emotion and motivation: the role of the amygdala, ventral striatum, and prefrontal cortex. Neurosci Biobehav Rev. 2002; 26:321-352. [PubMed: 12034134]

Chandra R, Lenz JD, Gancarz AM, Chaudhury D, Schroeder GL, Han MH, Cheer JF, Dietz DM, Lobo MK. Optogenetic inhibition of D1R containing nucleus accumbens neurons alters cocainemediated regulation of Tiam1. Front Mol Neurosci. 2013; 6:13. [PubMed: 23745104]

Chang HT, Kitai ST. Projection neurons of the nucleus accumbens: an intracellular labeling study. Brain Res. 1985; 347:112-116. [PubMed: 2996712]

Ciccocioppo R, Sanna PP, Weiss F. Cocaine-predictive stimulus induces drug-seeking behavior and neural activation in limbic brain regions after multiple months of abstinence: reversal by $\mathrm{D}(1)$ antagonists. Proc Natl Acad Sci U S A. 2001; 98:1976-1981. [PubMed: 11172061]

Cohen MX, Frank MJ. Neurocomputational models of basal ganglia function in learning, memory and choice. Behav Brain Res. 2009; 199:141-156. [PubMed: 18950662]

Dautan D, Huerta-Ocampo I, Witten IB, Deisseroth K, Bolam JP, Gerdjikov T, Mena-Segovia J. A major external source of cholinergic innervation of the striatum and nucleus accumbens originates in the brainstem. J Neurosci. 2014; 34:4509-4518. [PubMed: 24671996] 
Deniau JM, Chevalier G. The lamellar organization of the rat substantia nigra pars reticulata: distribution of projection neurons. Neuroscience. 1992; 46:361-377. [PubMed: 1542412]

Deutch AY, Bubser M, Young CD. Psychostimulant-induced Fos protein expression in the thalamic paraventricular nucleus. J Neurosci. 1998; 18:10680-10687. [PubMed: 9852603]

Di Chiara G, Imperato A. Drugs abused by humans preferentially increase synaptic dopamine concentrations in the mesolimbic system of freely moving rats. Proc Natl Acad Sci U S A. 1988; 85:5274-5278. [PubMed: 2899326]

Durieux PF, Bearzatto B, Guiducci S, Buch T, Waisman A, Zoli M, Schiffmann SN, de Kerchove d'Exaerde A. D2R striatopallidal neurons inhibit both locomotor and drug reward processes. Nat Neurosci. 2009; 12:393-395. [PubMed: 19270687]

Epstein DH, Preston KL, Stewart J, Shaham Y. Toward a model of drug relapse: an assessment of the validity of the reinstatement procedure. Psychopharmacology. 2006; 189:1-16. [PubMed: 17019567]

Everitt BJ, Robbins TW. Neural systems of reinforcement for drug addiction: from actions to habits to compulsion. Nat Neurosci. 2005; 8:1481-1489. [PubMed: 16251991]

Farrell MS, Pei Y, Wan Y, Yadav PN, Daigle TL, Urban DJ, Lee HM, Sciaky N, Simmons A, Nonneman RJ, Huang XP, Hufeisen SJ, Guettier JM, Moy SS, Wess J, Caron MG, Calakos N, Roth BL. A Galphas DREADD mouse for selective modulation of cAMP production in striatopallidal neurons. Neuropsychopharmacol. 2013; 38:854-862.

Ferguson SM, Eskenazi D, Ishikawa M, Wanat MJ, Phillips PE, Dong Y, Roth BL, Neumaier JF. Transient neuronal inhibition reveals opposing roles of indirect and direct pathways in sensitization. Nat Neurosci. 2011; 14:22-24. [PubMed: 21131952]

Ferguson SM, Neumaier JF. Using DREADDs to investigate addiction behaviors. Current Opinion in Behavioral Sciences. 2015; 2:69-72.

Finch DM. Neurophysiology of converging synaptic inputs from the rat prefrontal cortex, amygdala, midline thalamus, and hippocampal formation onto single neurons of the caudate/putamen and nucleus accumbens. Hippocampus. 1996; 6:495-512. [PubMed: 8953303]

Fowler CD, Kenny PJ. Utility of genetically modified mice for understanding the neurobiology of substance use disorders. Hum Genet. 2012; 131:941-957. [PubMed: 22190154]

Francis TC, Chaudhury D, Lobo MK. Optogenetics: illuminating the neural bases of rodent behavior. Open Access Animal Physiology. 2014; 6

Freund TF, Powell JF, Smith AD. Tyrosine hydroxylase-immunoreactive boutons in synaptic contact with identified striatonigral neurons, with particular reference to dendritic spines. Neuroscience. 1984; 13:1189-1215. [PubMed: 6152036]

Fujiyama F, Sohn J, Nakano T, Furuta T, Nakamura KC, Matsuda W, Kaneko T. Exclusive and common targets of neostriatofugal projections of rat striosome neurons: a single neuron-tracing study using a viral vector. Eur J Neurosci. 2011; 33:668-677. [PubMed: 21314848]

Gerfen CR, Herkenham M, Thibault J. The neostriatal mosaic: II. Patch- and matrix-directed mesostriatal dopaminergic and non-dopaminergic systems. J Neurosci. 1987; 7:3915-3934. [PubMed: 2891799]

Gerfen CR, Staines WA, Arbuthnott GW, Fibiger HC. Crossed connections of the substantia nigra in the rat. J Comp Neurol. 1982; 207:283-303. [PubMed: 7107988]

Gerfen CR, Surmeier DJ. Modulation of striatal projection systems by dopamine. Annu Rev Neurosci. 2011; 34:441-466. [PubMed: 21469956]

Goldstein RZ, Volkow ND. Drug addiction and its underlying neurobiological basis: neuroimaging evidence for the involvement of the frontal cortex. Am J Psychiatry. 2002; 159:1642-1652. [PubMed: 12359667]

Goldstein RZ, Volkow ND. Dysfunction of the prefrontal cortex in addiction: neuroimaging findings and clinical implications. Nat Rev Neurosci. 2011; 12:652-669. [PubMed: 22011681]

Grienberger C, Konnerth A. Imaging calcium in neurons. Neuron. 2012; 73:862-885. [PubMed: 22405199]

Groenewegen HJ, Berendse HW, Wolters JG, Lohman AH. The anatomical relationship of the prefrontal cortex with the striatopallidal system, the thalamus and the amygdala: evidence for a parallel organization. Prog Brain Res. 1990; 85:95-116. discussion 116-118. [PubMed: 2094917] 
Groenewegen HJ, Trimble M. The ventral striatum as an interface between the limbic and motor systems. CNS Spectr. 2007; 12:887-892. [PubMed: 18163034]

Groenewegen HJ, Wright CI, Beijer AV, Voorn P. Convergence and segregation of ventral striatal inputs and outputs. Ann N Y Acad Sci. 1999; 877:49-63. [PubMed: 10415642]

Grueter BA, Robison AJ, Neve RL, Nestler EJ, Malenka RC. FosB differentially modulates nucleus accumbens direct and indirect pathway function. Proc Natl Acad Sci U S A. 2013; 110:19231928. [PubMed: 23319622]

Haber SN. The primate basal ganglia: parallel and integrative networks. J Chem Neuroanat. 2003; 26:317-330. [PubMed: 14729134]

Haber SN, Calzavara R. The cortico-basal ganglia integrative network: the role of the thalamus. Brain Res Bull. 2009; 78:69-74. [PubMed: 18950692]

Haber SN, Fudge JL, McFarland NR. Striatonigrostriatal pathways in primates form an ascending spiral from the shell to the dorsolateral striatum. J Neurosci. 2000; 20:2369-2382. [PubMed: 10704511]

Haber SN, McFarland NR. The concept of the ventral striatum in nonhuman primates. Ann N Y Acad Sci. 1999; 877:33-48. [PubMed: 10415641]

Hamlin AS, Clemens KJ, Choi EA, McNally GP. Paraventricular thalamus mediates context-induced reinstatement (renewal) of extinguished reward seeking. Eur J Neurosci. 2009; 29:802-812. [PubMed: 19200064]

Heimer L, Alheid GF, de Olmos JS, Groenewegen HJ, Haber SN, Harlan RE, Zahm DS. The accumbens: beyond the core-shell dichotomy. J Neuropsychiatry Clin Neurosci. 1997; 9:354-381. [PubMed: 9276840]

Hikida T, Kimura K, Wada N, Funabiki K, Nakanishi S. Distinct roles of synaptic transmission in direct and indirect striatal pathways to reward and aversive behavior. Neuron. 2010; 66:896-907. [PubMed: 20620875]

Hiroi N, White NM. The amphetamine conditioned place preference: differential involvement of dopamine receptor subtypes and two dopaminergic terminal areas. Brain Res. 1991; 552:141-152. [PubMed: 1833032]

Hong S, Hikosaka O. Dopamine-mediated learning and switching in cortico-striatal circuit explain behavioral changes in reinforcement learning. Front Behav Neurosci. 2011; 5:15. [PubMed: 21472026]

Huang ZJ, Zeng H. Genetic approaches to neural circuits in the mouse. Annu Rev Neurosci. 2013; 36:183-215. [PubMed: 23682658]

Huston JP, Silva MA, Topic B, Muller CP. What's conditioned in conditioned place preference? Trends Pharmacol Sci. 2013; 34:162-166. [PubMed: 23384389]

James MH, Charnley JL, Flynn JR, Smith DW, Dayas CV. Propensity to 'relapse' following exposure to cocaine cues is associated with the recruitment of specific thalamic and epithalamic nuclei. Neuroscience. 2011; 199:235-242. [PubMed: 21985936]

James MH, Dayas CV. What about me...? The PVT: a role for the paraventricular thalamus (PVT) in drug-seeking behavior. Front Behav Neurosci. 2013; 7:18. [PubMed: 23509439]

Kalivas PW. The glutamate homeostasis hypothesis of addiction. Nat Rev Neurosci. 2009; 10:561572. [PubMed: 19571793]

Kalivas PW, Volkow ND. The neural basis of addiction: a pathology of motivation and choice. Am J Psychiatry. 2005; 162:1403-1413. [PubMed: 16055761]

Kelley AE, Schiltz CA, Landry CF. Neural systems recruited by drug- and food-related cues: studies of gene activation in corticolimbic regions. Physiol Behav. 2005; 86:11-14. [PubMed: 16139315]

Kemp JM, Powell TP. The structure of the caudate nucleus of the cat: light and electron microscopy. Philos Trans R Soc Lond B Biol Sci. 1971; 262:383-401. [PubMed: 4107495]

Kita H. GABAergic circuits of the striatum. Prog Brain Res. 1993; 99:51-72. [PubMed: 8108557]

Kita H, Chang HT, Kitai ST. Pallidal inputs to subthalamus: intracellular analysis. Brain Res. 1983; 264:255-265. [PubMed: 6303502]

Koo JW, Mazei-Robison MS, Chaudhury D, Juarez B, LaPlant Q, Ferguson D, Feng J, Sun H, Scobie KN, Damez-Werno D, Crumiller M, Ohnishi YN, Ohnishi YH, Mouzon E, Dietz DM, Lobo MK, 
Neve RL, Russo SJ, Han MH, Nestler EJ. BDNF is a negative modulator of morphine action. Science. 2012; 338:124-128. [PubMed: 23042896]

Koob GF, Volkow ND. Neurocircuitry of addiction. Neuropsychopharmacol. 2010; 35:217-238.

Kravitz AV, Freeze BS, Parker PR, Kay K, Thwin MT, Deisseroth K, Kreitzer AC. Regulation of parkinsonian motor behaviours by optogenetic control of basal ganglia circuitry. Nature. 2010; 466:622-626. [PubMed: 20613723]

Kravitz AV, Tye LD, Kreitzer AC. Distinct roles for direct and indirect pathway striatal neurons in reinforcement. Nat Neurosci. 2012; 15:816-818. [PubMed: 22544310]

Kreitzer AC, Malenka RC. Endocannabinoid-mediated rescue of striatal LTD and motor deficits in Parkinson's disease models. Nature. 2007; 445:643-647. [PubMed: 17287809]

Kress GJ, Yamawaki N, Wokosin DL, Wickersham IR, Shepherd GM, Surmeier DJ. Convergent cortical innervation of striatal projection neurons. Nat Neurosci. 2013; 16:665-667. [PubMed: 23666180]

Kufahl PR, Zavala AR, Singh A, Thiel KJ, Dickey ED, Joyce JN, Neisewander JL. c-Fos expression associated with reinstatement of cocaine-seeking behavior by response-contingent conditioned cues. Synapse. 2009; 63:823-835. [PubMed: 19533625]

Lee BR, Ma YY, Huang YH, Wang X, Otaka M, Ishikawa M, Neumann PA, Graziane NM, Brown TE, Suska A, Guo C, Lobo MK, Sesack SR, Wolf ME, Nestler EJ, Shaham Y, Schluter OM, Dong Y. Maturation of silent synapses in amygdala-accumbens projection contributes to incubation of cocaine craving. Nat Neurosci. 2013; 16:1644-1651. [PubMed: 24077564]

Lei W, Deng Y, Liu B, Mu S, Guley NM, Wong T, Reiner A. Confocal laser scanning microscopy and ultrastructural study of VGLUT2 thalamic input to striatal projection neurons in rats. J Comp Neurol. 2013; 521:1354-1377. [PubMed: 23047588]

Lenz JD, Lobo MK. Optogenetic insights into striatal function and behavior. Behav Brain Res. 2013; 255:44-54. [PubMed: 23628212]

Li S, Kirouac GJ. Projections from the paraventricular nucleus of the thalamus to the forebrain, with special emphasis on the extended amygdala. J Comp Neurol. 2008; 506:263-287. [PubMed: 18022956]

Li X, Wolf ME. Multiple faces of BDNF in cocaine addiction. Behav Brain Res. 2015; 279:240-254. [PubMed: 25449839]

Li Y, Wolf ME. Ibotenic acid lesions of prefrontal cortex do not prevent expression of behavioral sensitization to amphetamine. Behav Brain Res. 1997; 84:285-289. [PubMed: 9079793]

Lobo MK, Covington HE 3rd, Chaudhury D, Friedman AK, Sun H, Damez-Werno D, Dietz DM, Zaman S, Koo JW, Kennedy PJ, Mouzon E, Mogri M, Neve RL, Deisseroth K, Han MH, Nestler EJ. Cell type-specific loss of BDNF signaling mimics optogenetic control of cocaine reward. Science. 2010; 330:385-390. [PubMed: 20947769]

Lobo MK, Nestler EJ. The striatal balancing act in drug addiction: distinct roles of direct and indirect pathway medium spiny neurons. Front Neuroanat. 2011; 5:41. [PubMed: 21811439]

Lu XY, Ghasemzadeh MB, Kalivas PW. Expression of D1 receptor, D2 receptor, substance P and enkephalin messenger RNAs in the neurons projecting from the nucleus accumbens. Neuroscience. 1998; 82:767-780. [PubMed: 9483534]

Luo Z, Volkow ND, Heintz N, Pan Y, Du C. Acute cocaine induces fast activation of D1 receptor and progressive deactivation of $\mathrm{D} 2$ receptor striatal neurons: in vivo optical microprobe [Ca2+]i imaging. J Neurosci. 2011; 31:13180-13190. [PubMed: 21917801]

Luscher C, Malenka RC. Drug-evoked synaptic plasticity in addiction: from molecular changes to circuit remodeling. Neuron. 2011; 69:650-663. [PubMed: 21338877]

Ma YY, Lee BR, Wang X, Guo C, Liu L, Cui R, Lan Y, Balcita-Pedicino JJ, Wolf ME, Sesack SR, Shaham Y, Schluter OM, Huang YH, Dong Y. Bidirectional modulation of incubation of cocaine craving by silent synapse-based remodeling of prefrontal cortex to accumbens projections. Neuron. 2014; 83:1453-1467. [PubMed: 25199705]

MacAskill AF, Cassel JM, Carter AG. Cocaine exposure reorganizes cell type- and input-specific connectivity in the nucleus accumbens. Nat Neurosci. 2014; 17:1198-1207. [PubMed: 25108911]

MacAskill AF, Little JP, Cassel JM, Carter AG. Subcellular connectivity underlies pathway-specific signaling in the nucleus accumbens. Nat Neurosci. 2012; 15:1624-1626. [PubMed: 23143514] 
Marchant NJ, Li X, Shaham Y. Recent developments in animal models of drug relapse. Curr Opin Neurobiol. 2013; 23:675-683. [PubMed: 23374536]

Martin-Fardon R, Boutrel B. Orexin/hypocretin (Orx/Hcrt) transmission and drug-seeking behavior: is the paraventricular nucleus of the thalamus (PVT) part of the drug seeking circuitry? Front Behav Neurosci. 2012; 6:75. [PubMed: 23162448]

McFarland K, Davidge SB, Lapish CC, Kalivas PW. Limbic and motor circuitry underlying footshockinduced reinstatement of cocaine-seeking behavior. J Neurosci. 2004; 24:1551-1560. [PubMed: 14973230]

McFarland K, Kalivas PW. The circuitry mediating cocaine-induced reinstatement of drug-seeking behavior. J Neurosci. 2001; 21:8655-8663. [PubMed: 11606653]

McFarland K, Lapish CC, Kalivas PW. Prefrontal glutamate release into the core of the nucleus accumbens mediates cocaine-induced reinstatement of drug-seeking behavior. J Neurosci. 2003; 23:3531-3537. [PubMed: 12716962]

McGeorge AJ, Faull RL. The organization of the projection from the cerebral cortex to the striatum in the rat. Neuroscience. 1989; 29:503-537. [PubMed: 2472578]

Meredith GE, Baldo BA, Andrezjewski ME, Kelley AE. The structural basis for mapping behavior onto the ventral striatum and its subdivisions. Brain Struct Funct. 2008; 213:17-27. [PubMed: 18256852]

Moorman DE, James MH, McGlinchey EM, Aston-Jones G. Differential roles of medial prefrontal subregions in the regulation of drug seeking. Brain Res. 2014

Neisewander JL, Baker DA, Fuchs RA, Tran-Nguyen LT, Palmer A, Marshall JF. Fos protein expression and cocaine-seeking behavior in rats after exposure to a cocaine self-administration environment. J Neurosci. 2000; 20:798-805. [PubMed: 10632609]

Nestler EJ. Cellular basis of memory for addiction. Dialogues Clin Neurosci. 2013; 15:431-443. [PubMed: 24459410]

Ostrander MM, Badiani A, Day HE, Norton CS, Watson SJ, Akil H, Robinson TE. Environmental context and drug history modulate amphetamine-induced c-fos mRNA expression in the basal ganglia, central extended amygdala, and associated limbic forebrain. Neuroscience. 2003; 120:551-571. [PubMed: 12890524]

Panlilio LV, Goldberg SR. Self-administration of drugs in animals and humans as a model and an investigative tool. Addiction. 2007; 102:1863-1870. [PubMed: 18031422]

Park K, Volkow ND, Pan Y, Du C. Chronic cocaine dampens dopamine signaling during cocaine intoxication and unbalances D1 over D2 receptor signaling. J Neurosci. 2013; 33:15827-15836. [PubMed: 24089490]

Park WK, Bari AA, Jey AR, Anderson SM, Spealman RD, Rowlett JK, Pierce RC. Cocaine administered into the medial prefrontal cortex reinstates cocaine-seeking behavior by increasing AMPA receptor-mediated glutamate transmission in the nucleus accumbens. J Neurosci. 2002; 22:2916-2925. [PubMed: 11923456]

Pascoli V, Terrier J, Espallergues J, Valjent E, O'Connor EC, Luscher C. Contrasting forms of cocaine-evoked plasticity control components of relapse. Nature. 2014; 509:459-464. [PubMed: 24848058]

Pascoli V, Turiault M, Luscher C. Reversal of cocaine-evoked synaptic potentiation resets druginduced adaptive behaviour. Nature. 2012; 481:71-75. [PubMed: 22158102]

Pennartz CM, Ito R, Verschure PF, Battaglia FP, Robbins TW. The hippocampal-striatal axis in learning, prediction and goal-directed behavior. Trends Neurosci. 2011; 34:548-559. [PubMed: 21889806]

Phillips PE, Stuber GD, Heien ML, Wightman RM, Carelli RM. Subsecond dopamine release promotes cocaine seeking. Nature. 2003; 422:614-618. [PubMed: 12687000]

Phillipson OT, Griffiths AC. The topographic order of inputs to nucleus accumbens in the rat. Neuroscience. 1985; 16:275-296. [PubMed: 4080159]

Pickens CL, Airavaara M, Theberge F, Fanous S, Hope BT, Shaham Y. Neurobiology of the incubation of drug craving. Trends Neurosci. 2011; 34:411-420. [PubMed: 21764143] 
Pierce RC, Bell K, Duffy P, Kalivas PW. Repeated cocaine augments excitatory amino acid transmission in the nucleus accumbens only in rats having developed behavioral sensitization. $\mathrm{J}$ Neurosci. 1996; 16:1550-1560. [PubMed: 8778304]

Reiner A, Hart NM, Lei W, Deng Y. Corticostriatal projection neurons - dichotomous types and dichotomous functions. Front Neuroanat. 2010; 4:142. [PubMed: 21088706]

Reynolds JN, Hyland BI, Wickens JR. A cellular mechanism of reward-related learning. Nature. 2001; 413:67-70. [PubMed: 11544526]

Roberts DC, Koob GF. Disruption of cocaine self-administration following 6-hydroxydopamine lesions of the ventral tegmental area in rats. Pharmacol Biochem Behav. 1982; 17:901-904. [PubMed: 6817350]

Robinson DL, Venton BJ, Heien ML, Wightman RM. Detecting subsecond dopamine release with fast-scan cyclic voltammetry in vivo. Clin Chem. 2003; 49:1763-1773. [PubMed: 14500617]

Robinson TE, Berridge KC. The neural basis of drug craving: an incentive-sensitization theory of addiction. Brain Res Brain Res Rev. 1993; 18:247-291. [PubMed: 8401595]

Robinson TE, Berridge KC. The psychology and neurobiology of addiction: an incentive-sensitization view. Addiction. 2000; 95(Suppl 2):S91-117. [PubMed: 11002906]

Robinson TE, Berridge KC. Review. The incentive sensitization theory of addiction: some current issues. Philos Trans R Soc Lond B Biol Sci. 2008; 363:3137-3146. [PubMed: 18640920]

Rotllant D, Marquez C, Nadal R, Armario A. The brain pattern of c-fos induction by two doses of amphetamine suggests different brain processing pathways and minor contribution of behavioural traits. Neuroscience. 2010; 168:691-705. [PubMed: 20406670]

Seamans JK, Lapish CC, Durstewitz D. Comparing the prefrontal cortex of rats and primates: insights from electrophysiology. Neurotox Res. 2008; 14:249-262. [PubMed: 19073430]

See RE, Elliott JC, Feltenstein MW. The role of dorsal vs ventral striatal pathways in cocaine-seeking behavior after prolonged abstinence in rats. Psychopharmacology. 2007; 194:321-331. [PubMed: 17589830]

Sesack SR, Deutch AY, Roth RH, Bunney BS. Topographical organization of the efferent projections of the medial prefrontal cortex in the rat: an anterograde tract-tracing study with Phaseolus vulgaris leucoagglutinin. J Comp Neurol. 1989; 290:213-242. [PubMed: 2592611]

Sesack SR, Grace AA. Cortico-Basal Ganglia reward network: microcircuitry. Neuropsychopharmacol. 2010; 35:27-47.

Shalev U, Grimm JW, Shaham Y. Neurobiology of relapse to heroin and cocaine seeking: a review. Pharmacol Rev. 2002; 54:1-42. [PubMed: 11870259]

Shepherd GM. Corticostriatal connectivity and its role in disease. Nat Rev Neurosci. 2013; 14:278291. [PubMed: 23511908]

Smith RJ, Lobo MK, Spencer S, Kalivas PW. Cocaine-induced adaptations in D1 and D2 accumbens projection neurons (a dichotomy not necessarily synonymous with direct and indirect pathways). Curr Opin Neurobiol. 2013; 23:546-552. [PubMed: 23428656]

Song SS, Kang BJ, Wen L, Lee HJ, Sim HR, Kim TH, Yoon S, Yoon BJ, Augustine GJ, Baik JH. Optogenetics reveals a role for accumbal medium spiny neurons expressing dopamine D2 receptors in cocaine-induced behavioral sensitization. Front Behav Neurosci. 2014; 8:336. [PubMed: 25352792]

Stafford D, LeSage MG, Glowa JR. Progressive-ratio schedules of drug delivery in the analysis of drug self-administration: a review. Psychopharmacology. 1998; 139:169-184. [PubMed: 9784071]

Stefanik MT, Kalivas PW. Optogenetic dissection of basolateral amygdala projections during cueinduced reinstatement of cocaine seeking. Front Behav Neurosci. 2013; 7:213. [PubMed: 24399945]

Stefanik MT, Kupchik YM, Brown RM, Kalivas PW. Optogenetic evidence that pallidal projections, not nigral projections, from the nucleus accumbens core are necessary for reinstating cocaine seeking. J Neurosci. 2013; 33:13654-13662. [PubMed: 23966687]

Stefanik MT, Kupchik YM, Kalivas PW. Optogenetic inhibition of cortical afferents in the nucleus accumbens simultaneously prevents cue-induced transient synaptic potentiation and cocaineseeking behavior. Brain Struct Funct. 2015 
Steketee JD, Kalivas PW. Drug wanting: behavioral sensitization and relapse to drug-seeking behavior. Pharmacol Rev. 2011; 63:348-365. [PubMed: 21490129]

Stuber GD, Roitman MF, Phillips PE, Carelli RM, Wightman RM. Rapid dopamine signaling in the nucleus accumbens during contingent and noncontingent cocaine administration. Neuropsychopharmacol. 2005; 30:853-863.

Suska A, Lee BR, Huang YH, Dong Y, Schluter OM. Selective presynaptic enhancement of the prefrontal cortex to nucleus accumbens pathway by cocaine. Proc Natl Acad Sci U S A. 2013; 110:713-718. [PubMed: 23267100]

Swanson LW. The projections of the ventral tegmental area and adjacent regions: a combined fluorescent retrograde tracer and immunofluorescence study in the rat. Brain Res Bull. 1982; 9:321-353. [PubMed: 6816390]

Tang K, Low MJ, Grandy DK, Lovinger DM. Dopamine-dependent synaptic plasticity in striatum during in vivo development. Proc Natl Acad Sci U S A. 2001; 98:1255-1260. [PubMed: 11158626]

Torregrossa MM, Kalivas PW. Microdialysis and the neurochemistry of addiction. Pharmacol Biochem Behav. 2008; 90:261-272. [PubMed: 17928041]

Tripathi A, Prensa L, Cebrian C, Mengual E. Axonal branching patterns of nucleus accumbens neurons in the rat. J Comp Neurol. 2010; 518:4649-4673. [PubMed: 20886627]

Tye KM, Deisseroth K. Optogenetic investigation of neural circuits underlying brain disease in animal models. Nat Rev Neurosci. 2012; 13:251-266. [PubMed: 22430017]

Tzschentke TM. Measuring reward with the conditioned place preference paradigm: a comprehensive review of drug effects, recent progress and new issues. Prog Neurobiol. 1998; 56:613-672. [PubMed: 9871940]

Tzschentke TM, Schmidt WJ. Differential effects of discrete subarea-specific lesions of the rat medial prefrontal cortex on amphetamine- and cocaine-induced behavioural sensitization. Cereb Cortex. 2000; 10:488-498. [PubMed: 10847599]

Urban DJ, Roth BL. DREADDs (designer receptors exclusively activated by designer drugs): chemogenetic tools with therapeutic utility. Annu Rev Pharmacol Toxicol. 2015; 55:399-417. [PubMed: 25292433]

van Huijstee AN, Mansvelder HD. Glutamatergic synaptic plasticity in the mesocorticolimbic system in addiction. Front Cell Neurosci. 2014; 8:466. [PubMed: 25653591]

Vander Weele CM, Porter-Stransky KA, Mabrouk OS, Lovic V, Singer BF, Kennedy RT, Aragona BJ. Rapid dopamine transmission within the nucleus accumbens: dramatic difference between morphine and oxycodone delivery. Eur J Neurosci. 2014; 40:3041-3054. [PubMed: 25208732]

Volkow ND, Wang GJ, Tomasi D, Baler RD. Unbalanced neuronal circuits in addiction. Curr Opin Neurobiol. 2013; 23:639-648. [PubMed: 23434063]

Wall NR, De La Parra M, Callaway EM, Kreitzer AC. Differential innervation of direct- and indirectpathway striatal projection neurons. Neuron. 2013; 79:347-360. [PubMed: 23810541]

Weissenborn R, Whitelaw RB, Robbins TW, Everitt BJ. Excitotoxic lesions of the mediodorsal thalamic nucleus attenuate intravenous cocaine self-administration. Psychopharmacology. 1998; 140:225-232. [PubMed: 9860114]

White FJ, Kalivas PW. Neuroadaptations involved in amphetamine and cocaine addiction. Drug Alcohol Depend. 1998; 51:141-153. [PubMed: 9716936]

Willuhn I, Burgeno LM, Everitt BJ, Phillips PE. Hierarchical recruitment of phasic dopamine signaling in the striatum during the progression of cocaine use. Proc Natl Acad Sci U S A. 2012; 109:20703-20708. [PubMed: 23184975]

Willuhn I, Burgeno LM, Groblewski PA, Phillips PE. Excessive cocaine use results from decreased phasic dopamine signaling in the striatum. Nat Neurosci. 2014; 17:704-709. [PubMed: 24705184]

Willuhn I, Wanat MJ, Clark JJ, Phillips PE. Dopamine signaling in the nucleus accumbens of animals self-administering drugs of abuse. Curr Top Behav Neurosci. 2010; 3:29-71. [PubMed: 21161749] 
Wolf ME, Dahlin SL, Hu XT, Xue CJ, White K. Effects of lesions of prefrontal cortex, amygdala, or fornix on behavioral sensitization to amphetamine: comparison with N-methyl-D-aspartate antagonists. Neuroscience. 1995; 69:417-439. [PubMed: 8552239]

Xu ZC, Wilson CJ, Emson PC. Restoration of the corticostriatal projection in rat neostriatal grafts: electron microscopic analysis. Neuroscience. 1989; 29:539-550. [PubMed: 2739900]

Young CD, Deutch AY. The effects of thalamic paraventricular nucleus lesions on cocaine-induced locomotor activity and sensitization. Pharmacol Biochem Behav. 1998; 60:753-758. [PubMed: 9678661]

Zalocusky K, Deisseroth K. Optogenetics in the behaving rat: integration of diverse new technologies in a vital animal model. Optogenetics. 2013; 1:1-17.

Zhou L, Furuta T, Kaneko T. Chemical organization of projection neurons in the rat accumbens nucleus and olfactory tubercle. Neuroscience. 2003; 120:783-798. [PubMed: 12895518] 


\section{Highlights}

- Circuit regulation of addiction is complex and dynamic.

- The pattern and source of dopamine and glutamate neurotransmission in striatum is critical for shaping addictive processes.

- Novel techniques are providing new insights into the neural circuits that regulate addiction. 


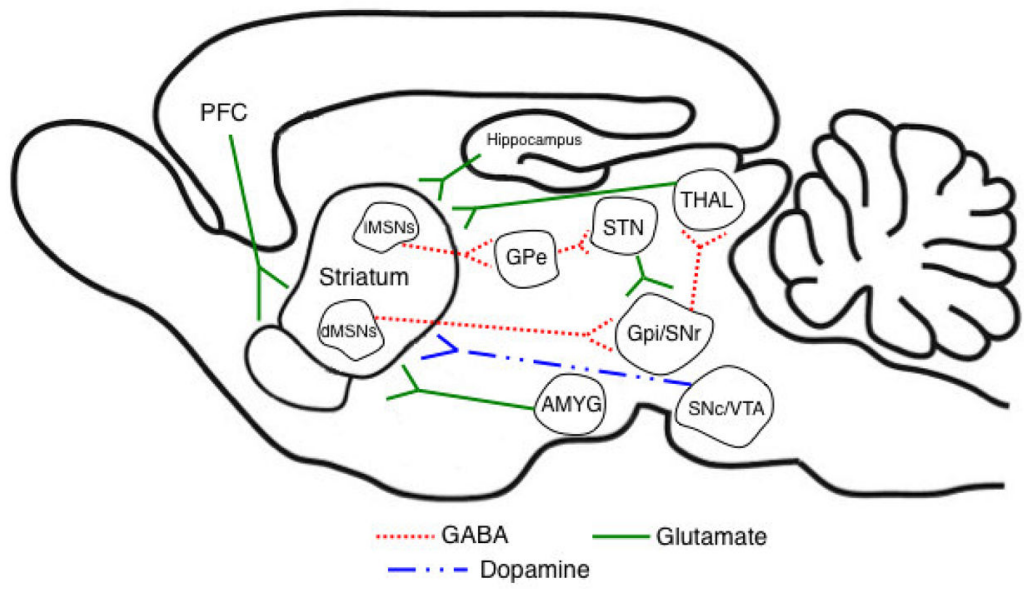

Fig. 1.

Simplified schematic view of striatal inputs and outputs. The striatum receives glutamatergic inputs (denoted in green) from the cortex, amygdala, hippocampus and thalamus and dopaminergic inputs (denoted in blue) from the VTA and SNc. Direct pathway striatal neurons (dMSNs) project monosynaptically to the GPi/SNr whereas indirect pathway striatal neurons (iMSNs) project to the GPi/SNr via the GPe/VP and STN. Red dashed lines denote GABAergic inhibitory projections. 


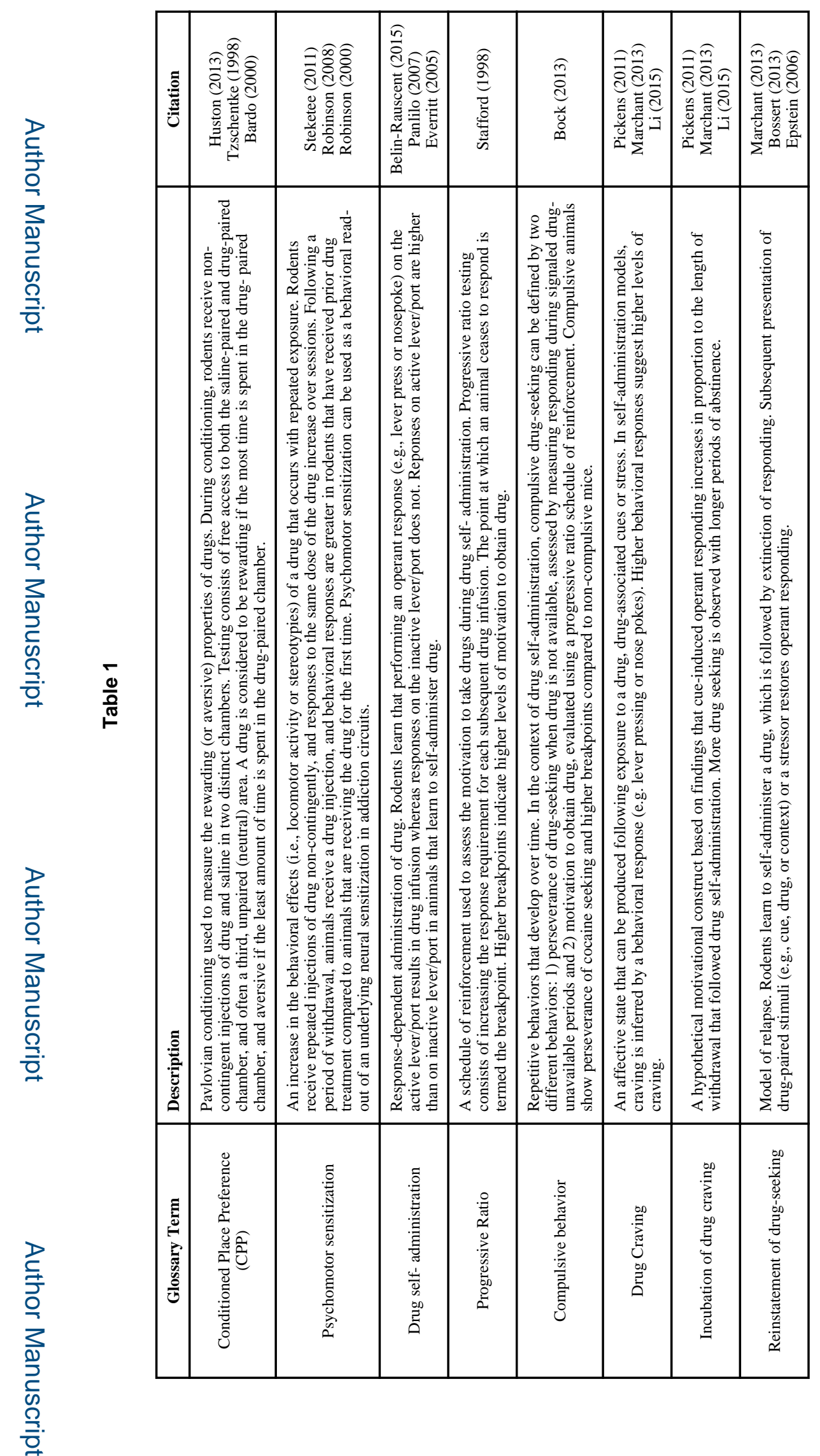

Neuroscience. Author manuscript; available in PMC 2016 August 20. 


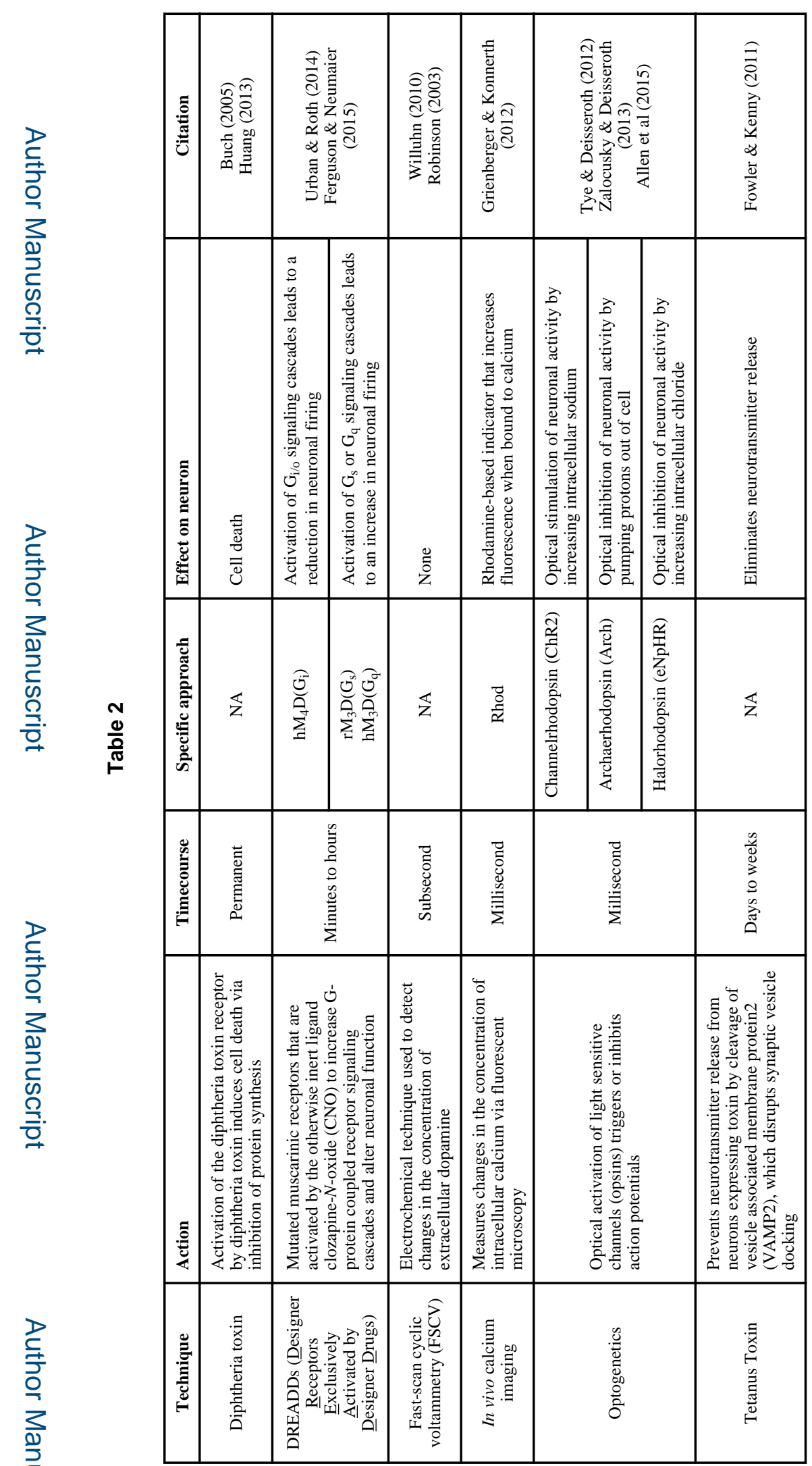

Neuroscience. Author manuscript; available in PMC 2016 August 20. 